\title{
The Impact of Strengthening Exercise on Dynamic Balance in Patients with Knee Osteoarthritis
}

SHENBAGA SUNDARAM SUBRAMANIAN ${ }^{1}$, MAKESH BABU SUBRAMANIAN ${ }^{2}$, RIZIQ ALLAH MUSTAFA GAOWGEH ${ }^{3}$, MIKHLED FALAH MAAYAH ${ }^{4}$, ZIYAD NEAMATALLAH ${ }^{5}$, THAMER AHMAD ALTAIM ${ }^{6}$, SAAD S ALFAWAZPH.D ${ }^{7}$, ALKHATEEB M. AFNAN ${ }^{8}$

${ }^{1}$ Associate Professor, Chettinad School of Physiotherapy Chettinad Academy of Research and Education, Chettinad Hospital and Research Institute, Kelambakkam-603103, Tamil Nadu, India.

${ }^{2}$ Principal \& Professor, Sree Anjaneya College Of Paramedical Sciences, Malabar Medical College Hospital \& Research Centre, Calicut, Kerala, India.

${ }^{3}$ Associate professor Department of Physical Therapy, Faculty of Medical Rehabilitation Sciences, King Abdulaziz University, Jeddah, Saudi Arabia ,rizikjoresearch@gmail.com

${ }^{4}$ Associate professor, Department of Occupational Therapy, Faculty of Rehabilitation Medical Sciences, King Abdulaziz University, Jeddah, Saudi Arabia, mhayaah@kau.edu.sa

${ }^{4}$ Associate professor, Department of Rehabilitation Sciences, Faculty of Applied Medical Sciences, Jordan University of Science and Technology, P. O. Box: 3030, Irbid 22110, Jordan, mikhledm@just.edu.jo

5,7,8 Assistant Professor, Department of Physical Therapy, Faculty of Medical Rehabilitation Sciences, King Abdulaziz University, Jeddah, Saudi Arabia zneamatallah@kau.edu.sa

${ }^{6}$ Assistant Professor, Department of Physical Therapy, College of Applied Medical Sciences, Jouf University, KSA

Corresponding author: Shenbaga Sundaram Subramanian, Email:dr.subramanian@care.edu.in, Cell: +919003913514

\begin{abstract}
:
Background: Knee osteoarthritis is characterised clinically by usage-related pain and/or functional limitation. OA that is associated with physical dysfunction and decline in health-related quality of life caused the main disability worldwide and is expected to increase due to aging and obesity rates and further load on the population and health system. The strengthening exercises that normally used is knee flexion and extensions, isometric quadriceps exercise, isometric hamstring exercise, and sit to stand to improve the balance.

Objectives: is to find out the impact of Strengthening exercise on Balance in patients with knee Osteoarthritis

Study Design: Quasi experimental study

Methods: Fifty-six $(n=56)$ of knee OA patients were involved in this study by judgemental sampling design. Researcher will first demonstrate and explain the Y-balance tools testing procedure based on Plisky and colleagues study. Participants are given to practice six trials before the formal testing, stated that SEBT have a significant learning effect and found that the reaching distances reached the longest distance after six trials and then will be constant.

Results: Independent t-test shows significant difference in only anterior direction. In the experimental group the mean value is 69.83 with a SD of 11.62 while in the control group the mean value is 63.51 with a SD of 11.36; $p$-value of .045 and t-value of 2.056. In postero-lateral directions result shows there is no significant difference, experimental group the mean value is 91.10 with a SD of 9.74 while in control group mean value is 90.88 with SD value of 12.68 ; p-value of .947 and t-value of .067. Result of postero-medial shows no significant difference too, in experimental group the mean value of 95.16 with SD of 10.92 while in control group the mean value is 93.40 with SD of $8.20 ; p=$ value of .501 and t-value of .678 .

Conclusion: This study has proven strengthening exercise using YBT improved only anterior direction of YBT but no significant difference in postero-lateral and postero-medial direction.
\end{abstract}

Key Words: Knee Osteoarthritis, Strengthening exercise, Dynamic Balance, Star excursion test

\section{INTRODUCTION}

Knee osteoarthritis is characterised clinically by usage-related pain and/or functional limitation. It is a common complex joint disorder showing focal cartilage loss, new bone formation and involvement of all joint tissues. Structural tissue changes are mirrored in classical radiographic features ${ }^{1}$. OA that is associated with physical dysfunction and decline in health-related quality of life caused the main disability worldwide and is expected to increase due to aging and obesity rates and further load on the population and health system ${ }^{2}$. Quadriceps weakness starts on the early stage of osteoarthritis knee that could be due to the progression of OA knee or straight to the cause of OA knee. Furthermore, the decrement of muscle strength in OA knee patient could be affected by joint pain, joint damage, effusion, lack of motivation or fear of further joint injury or pain ${ }^{3}$. The role of weakness in quadriceps act as a risk factor for the development of knee, OA is not fully understood but it is believed that the quadriceps function can act as a shock absorbers and stabilizers. Thus, weakness of quadriceps had caused excessive mechanical load on articular cartilage and led to degeneration of joint ${ }^{4}$. The population with knee OA was found to be having reduced in their dynamic balance and causes the increase of fall compared to healthy adults with the age and the gender-matched. They suggested that reduced quadriceps strength with a decrease in proprioception which both of it is commonly seen in OA knee patients could be the factors ${ }^{5}$. The reduced proprioception leads to altered gait and physiologically joint loading which result in progressive joint degeneration ${ }^{6}$. Reduced muscle strength and impaired muscle activation will contribute to poor muscle balance ${ }^{7}$. The reduction of strength that caused poor balance will increase the risk of fall as the muscle unable to produce adequate magnitude and rate of joint torques ${ }^{8}$. A study that compares independent strengthening exercise, independent balance exercise and combination of strengthening and balance exercise concluded that all the three groups of exercises showed improvement in the physical function ${ }^{9}$. In a systemic review, discover physical therapies that improve balance and reducing fall risk. 15 studies which include aerobic training, strengthen training, Tai-Chi, water-based exercise and light therapy are included in this systemic review with high methodological quality according to the Physiotherapy Evidence Database ${ }^{10}$. Star Excursion Balance Test (SEBT) is a tool which requires subjects to stand on one leg and reach for eight directions which include anterior, anteromedial, anterolateral, medial, lateral, posterior, posteromedial, posterolateral using another leg as far as possible. They are required to return to the original position without losing balance ${ }^{11}$. Objective of the study is to find out the impact of Strengthening exercise on Balance in patients with knee Osteoarthritis.

\section{METHODOLOGY}

This study will utilize a quantitative approach, quasi experimental design group research design to determine the effect of strengthening exercise on balance and muscle strength in patients with knee osteoarthritis. There is also a control of the interventions given, and a randomised allocation of patients to the control and experimental group with pre and post-test design. All procedures, 
interventions, and assessments tools that will be used in this study will undergo Ethics Review prior to the conduct of the study. Subjects that fulfil any 3 of the 1986 American College of Rheumatology (ACR) clinical criteria for knee OA and had Lequesne score of 1-7 ${ }^{12}$. Excluded the following criteria, had any lower limb realignment surgeries, Lower limb joint replacement, have gross ligament instability, Knee surgery for past 12 months, Lower limb fracture past 6 months, uses assistive device to help in mobility, Rheumatoid arthritis, have any severe cognitive, cardiorespiratory, neurological or musculoskeletal problem other than knee OA, participated in other treatment programmes catering to the lower limbs in the past year. Subjects who passed the study's inclusion and exclusion criteria will be selected using Judgmental Sampling. The design was adapted due to the strict inclusion criteria to produce valid results.

Procedure: Researcher will first demonstrate and explain the $Y$ balance tools testing procedure based on Plisky and colleagues study. Participants are given to practice six trials before the formal testing, stated that SEBT have a significant learning effect and found that the reaching distances reached the longest distance after six trials and then will be constant ${ }^{13}$. Participants were required to wear athletic shoes during the testing period. Participants stood on the central platform using single leg stance which is the limb that was diagnosed having $O A$ knee with the most distal part of athletic shoes at the starting line. Participants was asked to push the reach indicator as far as possible using the free limb and while maintaining the single leg stance in three directions which is anterior, postero-lateral and postero-medial in relation to stance foot. Standard testing order was developed and utilized in order to ensure the reproducibility of the test and launch a consistent testing protocol. The testing order required three successful trial on the affected limb but patients unable to perform it within six attempts it will consider the patients failed in that direction. During formal testing, participant was instructed to push the reach indicator in the direction that begin tested. These instructions are only given during formal testing period. All testing will be observed, scored and determined whether it is a successful trail by researcher. Distance are recorded only if it is a successful trial. Trial considered as failed if participants failed to sustain in single leg stance, failed to sustain contact with the reach indicator during reaching to the target area, weight was shifted to the reach indicator, unable to come back to the starting point with control. After the test of $y$-balance tools, participants joined a four weeks exercise program. Each session includes 2 minutes of warm up and cold down respectively followed by 20 minutes of exercise which include strengthening and balance exercise, if participant is from experimental group (EG) or 10 minutes of balance exercise if participant is from control group (CG). Participant will have one training supervised by researcher each week once and required to do exercise at home every day. Strengthening exercises comprised of sit to stand (STT) and step up and down (SUD). Ten repetition and three sets for each exercise. STT and SUD were chosen because they are more functional in active daily living as the age group of participants are more to older adults, these exercises reflect the daily activities such as, standing up from a chair and climbing the stairs. It is suitable for the elderly because they do not require strong muscles but the muscles needed according to their active daily living requirements. Study also shows that functional training is more beneficial as neuromuscular adaptations is highly related to task specificity, stated that ability to stand up and sit down is foundation to most ordinary actives daily living such as toileting and dressing ${ }^{14}$. STT is a practical intervention as it required minimal training, exist as routines in daily life, equipment needed is only a stable chair and has visible outcomes. STS had been proof to increase muscle activity of rectus femoris and vastus medialis to activate more type II fibres by efficiently improve the muscle contraction force during buttocks off in OA knee population ${ }^{15}$. Medial hamstring and gleuteus maximus was found to have peaked muscle activity after buttockoff movement and hamstring muscle are proved to be activated in knee extension via co-contraction in STS. As for SUD exercise, stated that it is widely handy and cost effective. Study stated that SUD able to elicit muscle activation as resistance exercise. They compare step test with three different heights which is $10 \mathrm{~cm}, 20$ $\mathrm{cm}, 30 \mathrm{~cm}$ and compare it with leg press and knee extension exercise. In vastus lateralis, the mean peak of vastus lateralis in SUD with $10 \mathrm{~cm}$ height is higher than leg press but lower than knee extension. However, SUD in $20 \mathrm{~cm}$ and $30 \mathrm{~cm}$ vastus lateralis mean peak activation is higher than both knee extension and leg press exercise ${ }^{16}$. Balance training include tandem walking, lateral dodging and forward and backward walking while looking at object that is placed at the side of pathway in the middle. Tandem walking is a validated dynamic balance test in healthy adults from 20-70 years old as it tendency to extremely narrow the base of support of participants ${ }^{17}$. Backward walking is found to be effective in dynamic balance in high school female athletes. It is believed that backward walking involve motor control and balance is better than forward walking because it involves more postural control compared to forward walking motor control and balance ${ }^{18}$.

\section{RESULTS}

Of the 56 patients diagnosed with knee OA that was recruited for this study was equally divided into experimental and control group. Baseline data demographic data are presented in Table 1.

Table 1 Demographic data of participants

Table 1 Demographic data of participants
\begin{tabular}{|l|l|l|l|}
\hline. & Experimental & Control & Total \\
\hline $\begin{array}{l}\text { Number of } \\
\text { participants }\end{array}$ & 28 & 28 & 56 \\
\hline $\begin{array}{l}\text { Age (Mean } \pm \\
\text { SD) }\end{array}$ & $58.68 \pm 5.67$ & $60.54 \pm 9.82$ & $59.61 \pm 8.00$ \\
\hline $\begin{array}{l}\text { Gender } \\
\text { (Mode, } \\
\text { percentage) }\end{array}$ & Female, 96.4\% & Female, 89.3\% & Female, 92.9\% \\
\hline
\end{tabular}

Both of experimental and control group having the same number of participants which is 28 of them. In experimental group, the average age is $58.68 \pm 5.67$ with female as majority gender of $96.4 \%$. In control group, the average age is $60.54 \pm 9.82$ with also having female as majority gender of $89.3 \%$. The mean age for both group is $59.61 \pm 8.00$ with female having $92.9 \%$.

Table 2 Paired sample test for experimental group
\begin{tabular}{|l|l|l|l|l|}
\hline Direction & $\begin{array}{l}\text { Pre-test } \\
(\text { Mean } \pm \text { SD) }\end{array}$ & $\begin{array}{l}\text { Post-test } \\
(\text { Mean } \pm \text { SD) }\end{array}$ & t-value & $p$-value \\
\hline Anterior & $59.65 \pm 10.50$ & $69.83 \pm 11.62$ & -5.675 & .000 \\
\hline $\begin{array}{l}\text { Postero- } \\
\text { lateral }\end{array}$ & $80.35 \pm 14.73$ & $91.09 \pm 9.74$ & -5.058 & .000 \\
\hline $\begin{array}{l}\text { Postero- } \\
\text { medial }\end{array}$ & $88.56 \pm 24.77$ & $95.16 \pm 10.92$ & -1.527 & .138 \\
\hline
\end{tabular}

Paired samples test in experimental group shows that there is significant difference in only anterior direction and postero-lateral direction. Significant difference in the scores of pre-tests in anterior direction mean $=59.65$ and $S D=10.50$ and post-test in anterior direction mean $=69.83$ and $S D=11.62 ; p$-value $=.000 ; \mathrm{t}-$ value $=-5.675$. Significant difference in the scores of pre-tests in postero-lateral direction mean $=80.35$ and $S D=14.75$ and post-test in postero-lateral direction mean $=91.09$ and $S D=9, .74 ; p$-value $=$ $.000 ; \mathrm{t}$-value $=-5.058$. In postero-medial directions, it shows no significant difference with pre-test mean $=88.56$ and $S D=24.77$ and post-test mean $=88.56$ and $S D=24.77 ; p$-value $=.138$; $\mathrm{t}$ value $=-1.527$

Table 3 Paired sample test for control group
\begin{tabular}{|l|l|l|l|l|}
\hline Direction & $\begin{array}{l}\text { Pre-test } \\
\text { (Mean } \pm \text { SD) }\end{array}$ & $\begin{array}{l}\text { Post-test } \\
(\text { Mean } \pm \text { SD) }\end{array}$ & -value & $p$-value \\
\hline Anterior & $51.49 \pm 6.46$ & $63.51 \pm 11.36$ & -6.165 & .000 \\
\hline $\begin{array}{l}\text { Postero- } \\
\text { lateral }\end{array}$ & $78.55 \pm 11.32$ & $90.88 \pm 12.68$ & -7.850 & .000 \\
\hline $\begin{array}{l}\text { Postero- } \\
\text { medial }\end{array}$ & $81.89 \pm 10.38$ & $93.41 \pm 8.21$ & -8.882 & .000 \\
\hline
\end{tabular}


Paired samples test in control group shows that there is significant difference in all directions. Significant difference in the scores of pre-tests in anterior direction mean $=51.49$ and $S D=$ 6.46 and post-test in anterior direction mean $=63.51$ and $S D=$ 11.36; $p$-value $=.000 ; t$-value $=-6.165$. Significant difference in the scores of pre-tests in postero-lateral direction mean $=78.55$ and $\mathrm{SD}=11.32$ and post-test in postero-lateral direction mean $=90.88$ and $\mathrm{SD}=12.68 ; \mathrm{p}$-value $=.000 ; \mathrm{t}$-value $=-7.850$. In posteromedial directions, significant difference in the score of pre-tests mean $=81.89$ and $S D=10.38$ and post-test mean $=93.41$ and SD $=8.21 ; \mathrm{p}$-value $=.000 ; \mathrm{t}$-value $=-8.882$.

Table 4 Independent t-test for two groups

\begin{tabular}{|l|l|l|l|l|}
\hline Direction & Group & Mean \pm SD & t-value & p-value \\
\hline \multirow{2}{*}{ Anterior } & EG & $69.83 \pm 11.62$ & \multirow{2}{*}{2.056} & \multirow{2}{*}{.045} \\
\cline { 2 - 3 } & CG & $63.51 \pm 11.36$ & & \\
\hline \multirow{2}{*}{ Postero-lateral } & EG & $91.10 \pm 9.74$ & \multirow{2}{*}{.067} & \multirow{2}{*}{.947} \\
\cline { 2 - 3 } & CG & $90.88 \pm 12.68$ & & \multirow{2}{*}{.678} \\
\hline \multirow{2}{*}{ Postero-medial } & EG & $95.16 \pm 10.92$ & \multirow{2}{*}{.501} \\
\cline { 2 - 3 } & CG & $93.40 \pm 8.20$ & & \\
\hline
\end{tabular}

Independent t-test shows significant difference in only anterior direction. In the experimental group the mean value is 69.83 with a SD of 11.62 while in the control group the mean value is 63.51 with a SD of 11.36; p-value of .045 and t-value of 2.056. In postero-lateral directions result shows there is no significant difference, experimental group the mean value is 91.10 with a SD of 9.74 while in control group mean value is 90.88 with SD value of 12.68; p-value of .947 and t-value of .067. Result of postero-medial shows no significant difference too, in experimental group the mean value of 95.16 with SD of 10.92 while in control group the mean value is 93.40 with SD of $8.20 ; p=$ value of .501 and $t$-value of .678 .

\section{DISCUSSION}

The primary finding of this study is that a four-weeks strengthening exercise using functional activities plus balance exercise in patients with knee OA improved dynamic balance measured by $Y$ balance tools in anterior direction but not posteromedial and posterolateral direction. In this study, only two functional activities that used as strengthening exercises which are sit to stand and step-up and down. This is different from other studies that used open and closed kinetic chain and strengthen hip and knee muscles. during STS activity in knee OA population, they will use the non-affected side to compensate the weakness of affected side. This could be the reason of this study did not have significant improvement in dynamic balance ${ }^{19}$. In this study, Y-balance tool was used to measure the dynamic balance as dynamic balance is providing multidirectional challenges that needed in ADL, during reaching in the anterior direction of SEBT required strength of vastusmedialis while in posterolateral it requires more strength of biceps femoris ${ }^{20}$. In this study, there is $92.85 \%$ of female that participates in this study. It is well known that OA affects more in women than male. OA is caused by the degeneration of articular cartilage and articular cartilage has oestrogen receptor ${ }^{21}$. Menopause caused a decrease in the production of oestrogen and leads to a higher risk of getting OA. In a study, they found out that the prevalence of $O A$ was the same in men and women below 50 years old. However, menopausal older women are more prone to knee OA than men, due to the decreased level of oestrogens ${ }^{22}$. In another study, they found that males have significantly more cartilage than females throughout their life and this could be the cause that males having a lower risk of getting OA. Study on healthy adults stated that annual cartilage loss of both tibial and patella cartilage and progression of tibio femoral cartilage defects are greater in females than males.

\section{CONCLUSION}

As a conclusion, OA knee highly affecting population these days causing physical disability limiting active daily living. The reduction of balance in knee OA can be due to weakness of muscles especially quadriceps muscle which is well known in OA knee populations. There are no specific tools to measure dynamic balance in patients with knee OA. Therefore, a four-week strengthening exercise using functional activities which is sit to stand and step up and down is conducted to investigate their effects on dynamic balance. However, this study has proven strengthening exercise using YBT improved only anterior direction of YBT but no significant difference in postero-lateral and posteromedial direction.

\section{REFERENCES}

Zhang W, Doherty M, Peat G, Bierma-Zeinstra MA, Arden NK, Bresnihan B, Herrero-Beaumont G, Kirschner S, Leeb BF, Lohmander LS, Mazières B. EULAR evidence-based recommendations for the diagnosis of knee osteoarthritis Annals of the rheumatic diseases. 2010 Mar 1;69(3):483-9.

2 Kiadaliri AA, Lohmander LS, Moradi-Lakeh M, Petersson IF, Englund M. High and rising burden of hip and knee osteoarthritis in the Nordic region, 1990-2015: Findings from the Global Burden of Disease Study 2015. Acta orthopaedica. Findings from the Global 2018 Mar 4;89(2):177-83.

3 Dıraçoğlu D, Başkent A, Yağcı İ, Oezcakar L, Aydın R. ISOKINETIC STRENGTH MEASUREMENTS IN EARLY KNEE OSTEDARTHRITIS. Acta reumatologica portuguesa. 2009 Jan $1 ; 34(1)$

4 Øiestad BE, Juhl CB, Eitzen I, Thorlund JB. Knee extensor muscle weakness is a risk factor for development of knee osteoarthritis. A systematic review and metaanalysis. Osteoarthritis and Cartilage. 2015 Feb 1;23(2):171-7.

5 Takacs J, Krowchuk NM, Garland SJ, Carpenter MG, Hunt MA. Dynamic balance training improves physical function in individuals with knee osteoarthritis: a pilot training improves physical function in individuals with knee osteoarthritis: a pilot randomized controlled trial.
2017 Aug 1;98(8):1586-93.

6 Goel A, Agrawal S, Verman M. Effect of balance exercises on balance, pain and functional performance in osteoarthritis knee. Indian Journal of Physical Therapy. 2014;2(1):71-8

7 Liu C, Wan Q, Zhou W, Feng X, Shang S. Factors associated with balance function in patients with knee osteoarthritis: An integrative review. International journal of nursing sciences. 2017 Oct 10;4(4):402-9.

8 Cebolla EC, Rodacki AL, Bento PC. Balance, gait, functionality and strength: comparison between elderly fallers and non-fallers. Brazilian journal of physical therapy. 2015 Apr 27; 19:146-51.

9 Rogers MW, Tamulevicius N, Semple SJ, Krkeljas Z. Efficacy of home-based kinesthesia, balance \& agility exercise training among persons with symptomatic knee osteoarthritis. Journal of sports science \& medicine. 2012 Dec;11(4):751.

10 Mat S, Tan MP, Kamaruzzaman SB, Ng CT. Physical therapies for improving balance and reducing falls risk in osteoarthritis of the knee: a systematic review. Age and ageing. 2014 Aug 22;44(1):16-24.

11 Gribble PA, Hertel J, Plisky P. Using the Star Excursion Balance Test to assess dynamic postural-control deficits and outcomes in lower extremity injury: a dynamic postural-control deficits and outcomes in lower extremity injury: a
literature and systematic review. Journal of athletic training. 2012;47(3):339-57.

12 Basaran S, Guzel R, Seydaoglu G, Guler-Uysal F. Validity, reliability, and comparison of the WOMAC osteoarthritis index and Lequesne algofunctional index in Turkish patients with hip or knee osteoarthritis. Clinical rheumatology. 2010 Jul 1;29(7):749-56.

13 Plisky PJ, Gorman PP, Butler RJ, Kiesel KB, Underwood FB, Elkins B. The reliability of an instrumented device for measuring components of the star excursion balance test. North American journal of sports physical therapy: NAJSPT. 2009 May;4(2):92.

14 Baggen RJ, Van Roie E, van Dieën JH, Verschueren SM, Delecluse C. Weight bearing exercise can elicit similar peak muscle activation as medium-high intensity resistance exercise in elderly women. European journal of applied physiology. 2018 Mar; 118(3):531-41

15 Anan M, Shinkoda K, Suzuki K, Yagi M, Kito N. Dynamic frequency analyses of lower extremity muscles during sit-to-stand motion for the patients with knee osteoarthritis. PloS one. 2016 Jan 25;11(1):e0147496.

16 Mair JL, Boreham CA, Ditroilo M, McKeown D, M. Lowery M, Caulfield B, De Vito G. Benefits of a worksite or home-based bench stepping intervention for sedentary middle-aged adults-a pilot study. Clinical Physiology and Functional sedentary middle-aged adults-
Imaging. 2014 Jan;34(1):10-7.

17 Robertson M, Gregory R. Concurrent validation of the tandem walk test as a measure of dynamic walking balance in a healthy population. Phys Ther Rehabil.. 2017;4:12.

18 Jamshidi A, Etefagh F, Nickjoo A. Walking Backwards Improves High School Female Athletes' Balance. J Res Med Dent Sci. 2017;5(1):46-8.

19 Petrella M, Selistre LF, Serrão PR, Lessi GC, Gonçalves GH, Mattiello SM. Kinetics, kinematics, and knee muscle activation during sit to stand transition in unilateral and bilateral knee osteoarthritis. Gait \& Posture. 2021 May 1;86:38-44. unilateral and bilateral knee osteoarthritis. Gait \& Posture. 2021 May 1;86:38-44.
Wilson BR, Robertson KE, Burnham JM, Yonz MC, Ireland ML, Noehren B. The Wilson BR, Robertson KE, Burnham JM, Yonz MC, Ireland ML, Noehren B. The
relationship between hip strength and the $Y$ balance test. Journal of sport relationship between hip strength and
rehabilitation. 2018 Sep 1;27(5):445-50.

21 Price MD, Herndon JH. Gender differences in osteoarthritis. Menopause. 2009 Jul 1;16(4):624-5.

22 Wluka AE, Cicuttini FM, Spector TD. Menopause, oestrogens and arthritis. Maturitas. 2000 Jun 30;35(3):183-99. 